\title{
EDUCAÇÃO EM VALORES MORAIS NUMA PERSPECTIVA TRANSDISCIPLINAR
}

\author{
Daniel Skrsypcsak ${ }^{1}$ \\ Douglas Orestes Franzen²
}

\begin{abstract}
RESUMO
Este artigo tem como objetivo refletir sobre a educação em valores morais numa perspectiva transdisciplinar. Estender essa discussão, a partir das instituições que oferecem a educação pública básica, nos faz pensar na necessidade de criação de um projeto institucional tendo como pano de fundo a transdisciplinaridade. A partir de uma revisão bibliográfica, trouxemos para o debate autores que se debruçam sobre a temática e que podem contribuir para aprofundar a discussão. Para atender ao propósito do trabalho, estruturamos o mesmo em três momentos: no primeiro apresentamos algumas considerações em relação à ética sob a perspectiva da complexidade de Edgar Morin, no segundo momento abordamos algumas questões conceituais sobre a transdiciplinaridade, tendo em Basarab Nicolescu o principal autor utilizado e, no terceiro, problematizamos como os valores morais podem ser trabalhados na escola pública, buscando na transdisciplinaridade uma possibilidade de discussão. Defendemos a possibilidade de elaboração de um projeto institucional em torno da temática, em que todas as ações e relações da escola tenham os valores morais explicitados de forma consciente e intencional. Acreditamos que a escola não pode se silenciar para essa questão, buscando um consenso sobre determinados valores morais indispensáveis para a formação integral.
\end{abstract}

Palavras-chave: Complexidade. Transdisciplinaridade. Educação em valores morais.

\section{MORAL VALUES EDUCATION IN A TRANSDISCIPLINARY PERSPECTIVE}

\section{ABSTRACT}

This article aims to reflect about moral values education in a transdisciplinary perspective. Extending this discussion from institutions that offer basic public education leads us to think about the need of implementing an institutional project having as a background the transdisciplinarity. From a bibliographical review we have brought to the debate authors that study the subject and that can contribute to the discussion. In order to fulfill the purpose of the work we structured it in three moments: firstly we have shown some considerations regarding the ethics from the complexity of Edgar Morin perspective. In the second moment we approached some conceptual questions about the transdisciplinarity, being Basarab Nicolescu the main author used. In the third moment we discussed how moral values could be worked in public school seeking in transdisciplinarity a discussion possibility. We defend the possibility of elaborating an institutional project around the theme where all the school's actions and relationships will have the moral values explicitly explained in a conscious and intentional way. We believe that the school cannot be silent about this issue, seeking a consensus on certain moral values indispensable for integrity.

Keywords: Complexity. Transdisciplinarity. Moral values education.

Recebido em: 5/3/2018

Aceito em: 5/9/2018

${ }^{1}$ Doutorando em Educação nas Ciências pela Unijuí-RS. Professor do Centro Universitário Fai-Uceff e da rede pública do Estado de Santa Catarina.dskrsypcsak@hotmail.com

2Doutor em História pela UPF-RS. Professor do Centro Universitário Fai-Uceff. douglas@uceff.edu.br 
A discussão sobre a Educação em Valores Morais atualmente tem ganhado força em razão do cenário político e econômico em que vivemos. Estender essa discussão a partir das instituições sociais, mais especificamente as instituições que oferecem a educação pública básica, nos faz questionar: Quais são os valores que a escola busca e deve ter como meta desenvolver? Esses valores são possíveis de serem desenvolvidos?Desde os gregos convivemos com dilemas nessa ordem: A virtude pode ser ensinada? Aqui, nos parece pertinente recuperar esse questionamento refazendo o mesmo: A ética pode ser ensinada? Ou ainda: Os valores morais podem ser ensinados? A partir dessas questões, o objetivo é discutir a educação em valores morais a partir de um projeto institucional numa perspectiva transdisciplinar. Defendemos a necessidade de uma educação em valores morais nas escolas de forma intencional e sistemática. Para empreender esse esforço, dividimos o trabalho em três momentos.

No primeiro momento pretende-se discutir a ética trazendo alguns pontos contemplados na obra $O$ Método 6: Ética (2011), de Edgar Morin. Longe de buscar uma conceituação em relação à ética, o que se pretende é definir como pano de fundo a discussão acerca de uma educação em valores morais, trazendo o mesmo à luz da complexidade e projetando na transdisciplinaridade uma possibilidade de se materializar um projeto educativo. Optou-se pela obra do referido autor por ser a complexidade um princípio da transdisciplinaridade. No segundo momento, a partir de algumas ideias do pensamento complexo, busca-se compreender e conceituar a transdisciplinaridade. Para tanto, trazemos algumas ideias centrais de Basarab Nicolescu, um dos autores que sistematizou elementos fundamentais para elucidar a transdisciplinaridade. Esse esforço de tentar conceituar e caracterizar a mesma, se deve ao fato de procurar encontrar saídas ou alternativas para pensarmos a escola como uma entidade ou instituição que esteja engajada com uma educação em valores morais, tendo como pano de fundo a transdiciplinaridade como concepção metodológica.

No terceiro e último momento, anterior às considerações provisórias, busca-se apresentar a ética e a educação em valores morais discutidas, desenvolvidas ou "ensinadas", constituindo-se como um projeto institucional com validade perene e não como uma ação isolada, pautado na transdisciplinaridade. Serão evidenciadas e discutidas possibilidades de pensar a escola atual e do futuro, principalmente a partir das ideias de Maria Cândida de Morais e Juan Miguel Batalloso Navas. Essa discussão busca romper com a separação do conhecimento, não necessariamente a partir do abandono das disciplinas, mas pela forma de pensar a educação superando a fragmentação do conhecimento e projetando uma educação em valores morais.

\section{A ÉTICA SOB O OLHAR DA COMPLEXIDADE}

Não se pretende aqui entrar na discussão conceitual em relação ao termo ética como normalmente acontece nos trabalhos referentes a esse tema. Também não nos interessa refazer o percurso histórico que o termo atravessou ao longo dos períodos para pensá-la nos dias atuais. Muito menos apresentar um conceito que reflete nossas convicções ou suspeitas sobre o mesmo, até porque esse exercício se encontra em fase de elaboração e das primeiras aproximações. A discussão sobre a ética estará pautada principalmente a partir das ideias de Edgar Morin e, mais especificamente, em sua 
obra O método 6: Ética (2011). A tentativa é estabelecer algumas relações para a discussão posterior sobre a educação em valores morais numa perspectiva transdisciplinar. A complexidade se caracteriza como um dos pilares da transdisciplinaridade, fato este que contribui por essa opção.

A complexidade surge no momento da "passagem para o nosso mundo, necessariamente caracterizado por quatro dimensões e por energias acessíveis muito menores" (NICOLESCU, 1999, p. 20). Nesse sentido, as teorias unificadas são muito poderosas na esfera dos princípios gerais, mas na descrição da complexidade de nosso próprio nível são bastante pobres. A complexidade mostra-se por todas as partes, seja nas ciências exatas, humanas, etc. Morin (2013, p. 65) acrescenta que complexidade diz respeito ao "duplo desafio da religação e da incerteza"; religar o que se acreditava estar separado, fazer a certeza interagir com a certeza. $O$ autor esclarece que

complexus significa o que foi tecido junto: de fato, há complexidade quando elementos diferentes são inseparáveis constituídos do todo, [...] e há um tecido interdependente, interativo e inter-retroativo entre o objeto de conhecimento e seu contexto, as partes e o todo, o todo e as partes, as partes entre si (MORIN, 2000, p. 38).

Aproximando a complexidade do nosso objeto de estudo, ou seja, a ética e a educação em valores, Araújo (2007) considera que a teoria da complexidade aponta perspectivas de como é possível compreender a construção de valores morais nas inter-relações concebíveis entre os indivíduos. Para o autor, o modelo da complexidade possibilita transitar em um novo universo de explicações quando nos referimos à construção de valores, explicações estas mais próximas aos princípios de incerteza, indeterminação e acaso. Promover uma educação em valores não é tarefa fácil, porém os caminhos estão abertos. Dessa forma, considera-se uma opção factível no ambiente escolar.

Não é possível chegar à complexidade por meio de uma definição prévia, nem temos essa pretensão, sendo necessário percorrer caminhos diversos e nos perguntar se há complexidades e/ou uma complexidade em relação aos valores. Nesse sentido, a ética não pode escapar dos problemas da complexidade obrigando-nos à reflexão das relações entre o conhecimento, ciência, política com a ética e, mais especificamente, em nossa discussão com o contexto educativo. A ética é considerada por Morin um dos saberes fundamentais e necessários para a educação do futuro.

Para Morin (2011), a ética se manifesta de maneira imperativa como uma exigência moral.

O seu imperativo origina-se numa fonte interior ao indivíduo, que sente no espírito como a injunção de um dever. Mas ele provém também de uma fonte externa: a cultura, as crenças, as normas de uma comunidade. Há, certamente, também uma fonte anterior, originária da organização viva, transmitida geneticamente. Essas três fontes são interligadas como se tivessem um lençol subterrâneo em comum (p. 19).

O autor busca os imperativos em três fontes: uma fonte interna, regida pela consciência do sujeito, uma fonte externa, representada pela cultura, pelas crenças e pelas normas preestabelecidas na comunidade, e uma fonte anterior, transmitida geneticamente. Para o autor, a ética é constitutiva da natureza humana, pois, dentre outros atributos, nós somos seres de ética, e, sem ela, perdemos nossa humanidade. 
Falar de ética é falar de moral. Consoante Morin (2011), o ato moral é um ato de religação do indivíduo com a sociedade, com o outro e com a espécie humana. Esse ato seria capaz de provocar regeneração nas relações humanas. Nessa discussão, o autor faz a relação entre o egoísmo e o altruísmo e como a comunidade influencia nessa relação. "O sentimento de comunidade é e será fonte de responsabilidade e de solidariedade, sendo estas, por seu turno, fontes éticas" (p. 23, grifo do autor).

Utilizando-se de Pascal, Morin (2011) considera que a ética deve ser utilizada no enfrentamento da complexidade da vida e do mundo via mobilização da inteligência. Ele entende que a própria ética é complexa e necessita desse enfrentamento. Nesse sentido, considera que o pensamento complexo reconhece a autonomia da ética numa religação entre o saber e o dever, produzindo uma ética da solidariedade e não da coerção.

Todo conhecimento pode ser posto a serviço da manipulação, mas o pensamento complexo conduz a uma ética da solidariedade e da não-coerção [...], podemos imaginar que uma ciência que traga possibilidades de autoconhecimento abra-se para a solidariedade cósmica, não desintegre o rosto dos seres e dos entes, reconheça o mistério e, todas as coisas; poderia estabelecer um princípio de ação que não ordene, mas organize, não manipule, mas comunique, não dirija, mas estimule (MORIN, 2011, p. 64).

O autor considera o pensamento complexo um substrato para a ética e, ao buscar a religação dos conhecimentos, busca da mesma forma religar os seres humanos que outrora foram separados, ou que ainda continuam fragmentados e isolados.

A finalidade ética considera uma resistência à crueldade e à barbárie, e busca a realização da vida humana. Para Morin (2011, p. 202), "Viver humanamente é assumir plenamente as três dimensões da identidade humana: a identidade individual, a identidade social e a identidade antropológica. É, sobretudo viver poeticamente a vida". A expressão utilizada em seu livro - Muss es sein? Es muss seins! ${ }^{3}$ - evidencia uma ética da aposta nos fragmentos do bem imersos na imensidão da barbárie, crueldade e maldade. Como empreender essa tarefa não se sabe ao certo; o que se tem clareza é que a educação pode e deve contribuir nessa missão. $O$ bom pensamento é o pensamento que toma a condição humana em sua complexidade e nutre, dessa forma, a capacidade de julgamento ético do sujeito.

Para Moraes e Navas (2015b, p. 146), "É urgente pensar sobre os novos desafios éticos e os respectivos valores morais que norteiam o comportamento humano em sociedade $[. . .]^{\prime \prime}$. Longe de deixar claro o entendimento conceitual sobre a ética, o esforço aqui compreendeu uma tentativa de suscitar a discussão para uma possibilidade de projeto transdisciplinar, tendo como foco a ética e uma educação em valores morais. Conforme Moraes e Navas (2015b), precisamos nos aproximar de uma ética comple$x a$, que integra, que inclui e que seja transdisciplinar, o que é imprescindível em nosso tempo atual. Os autores, a partir de Manfred Max-Nef (2004), apontam "que a ética é

${ }^{3}$ Numa tradução literal significa: Tem de ser? Tem de ser! 
o saber humano mediante o qual podemos perceber, com maior clareza, o conceito de transdisciplinaridade, porque ele atravessa e preside, em última instância, todos os saberes" (p. 147).

Para Moraes e Navas (2015b), a ética pode ser considerada de natureza transdisciplinar, pois perpassa, de modo transversal, o processo educativo. Este processo educativo fundamenta-se em valores, não sendo possível, nesse contexto, a neutralidade. Não existindo uma educação neutra, ela sempre está impregnada de valores, não sendo possível uma educação sem valores. Dessa forma, considerar a educação em valores a partir dos processos educacionais pela transdisciplinaridade, requer compreender, mesmo que de forma inicial, algumas características sobre o olhar transdisciplinar. Assim, o próximo passo é tecer algumas considerações sobre a mesma. Não estamos tentando fazer o movimento das partes para o todo, mas, sim, separar didaticamente para esclarecer alguns pontos, mesmo que seja ainda de modo superficial.

\section{TRANSDISCIPLINARIDADE: Conceito Numa Perspectiva de Educação}

O que é e o que entendemos por transdisciplinaridade? O que é uma prática pedagógica transdisciplinar? Ao tentar responder essas questões não se pretende esgotar essa discussão, pois a mesma suscita ainda muitos debates. Precisamos levantar, porém, algumas questões para que, a partir de um melhor entendimento, possamos discutir uma alternativa para o debate de uma educação em valores morais, tendo na transdisciplinaridade uma possibilidade emergente.

A transdisciplinaridade nasce da necessidade de um novo conhecimento, um conhecimento global, do todo, que busca romper com a fragmentação que as disciplinas impuseram ao mundo. Para Morin (2000, p. 47-48), "o humano continua esquartejado, partido como pedaços de um quebra-cabeça ao qual falta uma peça". Segundo o autor, a especialização que foi tomando conta do mundo vem descaracterizando o próprio ser humano, no momento em que cada saber é dissociado do contexto global, fechado em suas próprias especialidades e verdades descontextualizadas.

Um autor que sistematizou elementos fundamentais para elucidar a Transdisciplinaridade é Basarab Nicolescu (1999). Nas palavras do autor

A transdisciplinaridade, como o prefixo "trans" indica, diz respeito àquilo que está ao mesmo tempo entre as disciplinas, através das diferentes disciplinas e além de qualquer disciplina. Seu objetivo é a compreensão do mundo presente, para o qual um dos imperativos é a unidade do conhecimento (p. 11).

Esse entendimento, segundo Moraes e Navas (2015a), revela um pouco a natureza da palavra a partir da sua etiologia, indicando aquilo que transcende o disciplinar. Para os autores, além das disciplinas está o sujeito, o ser humano inserido numa realidade complexa a ser desvelada. Configura-se numa epistemologia do sujeito, que, conforme Patrick Paul (2012 apud MORAES; NAVAS, 2015a, p. 77), “[...] se integra ao objeto e aos objetivos científicos e com eles se articula, desembocando em um além das disciplinas científicas, abrindo o campo do conhecimento aos saberes não acadêmicos e ao autoconhecimento". 
Nesta perspectiva, a transdisciplinaridade se interessa pela "dinâmica gerada pela ação de vários níveis de realidade ao mesmo tempo. A descoberta desta dinâmica passa pelo conhecimento disciplinar" (NICOLESCU, 1999, p. 12). A transdisciplinaridade não se configura como uma nova disciplina; esta alimenta-se da pesquisa disciplinar, que é também "iluminada de maneira nova e fecunda pelo conhecimento transdisciplinar. Neste sentido, as pesquisas disciplinares e transdisciplinares não são antagonistas mas complementares" (NICOLESCU, 1999, p. 13).

A transdisciplinaridade não é contrária às disciplinas, pois, como apontado anteriormente, os conhecimentos disciplinares e transdisciplinares não se antagonizam, mas se complementam. Entende-se que a transdisciplinaridade surgiu da necessidade de religar os conhecimentos das disciplinas e não pretende o fim das mesmas; o que se modifica é a maneira como estas são trabalhadas. Mesmo reconhecendo a diferença entre transdisciplinaridade, disciplinaridade, pluridisciplinaridade e interdisciplinaridade, "seria extremamente perigoso absolutizar esta distinção, pois neste caso a transdisciplinaridade seria esvaziada de todo seu conteúdo e sua eficácia na ação seria reduzida a nada" (NICOLESCU, 1999, p. 13).

Como supraindicado, a transdisciplinaridade não é independente dos conhecimentos parcelados, não é a certeza absoluta, e sim uma rede de teorias e práticas que se entrelaçam, em perspectivas que podem ser antagônicas, ou até complementares, fornecendo subsídios para a construção de conhecimentos diferentes dos que estão expostos. O que a transdisciplinaridade exige também é uma postura de "democracia cognitiva", considerando todos os saberes importantes, ultrapassando o preconceito e a hierarquização dos mesmos. Por meio dessa hierarquização, criou-se a crença de que são nobres os conhecimentos das ciências exatas, enquanto os das ciências humanas são menos importantes (MORIN, 2000).

Os conhecimentos de diferentes áreas estão ligados a um todo complexo, quando nenhum é melhor que o outro e todos têm seu papel e sua importância; não são contrários uns aos outros, mas complementares. É importante destacar a relevância da transdisciplinaridade para a própria disciplina. Se a disciplina considerar-se soberana no saber, sem ligação com os demais saberes, ela própria se anula enquanto ciência, pois um conhecimento somente é relevante se o mesmo estiver situado num determinado contexto (MORIN, 2015).

A metodologia transdisciplinar colabora na promoção da alteridade e do respeito ao pensamento do outro. Constitui-se num princípio epistemológico com base no sujeito visto como um ser humano integral e integrado numa dinâmica complexa. O que determina a metodologia da pesquisa transdisciplinar são seus pilares: níveis de realidade, a lógica do terceiro incluído e a complexidade. Não nos cabe nesse momento aprofundar ou caracterizar cada nível, porém é importante destacar que esses níveis proporcionarão a criação de métodos e modelos adequados a situações específicas e práticas.

Segundo Nicolescu (1999), a partir da metodologia transdisciplinar a prática da mesma pode se manifestar encarnando em cada ação um conjunto de métodos adaptados em cada situação específica. A definição e formulação desses métodos e ações devem estar relacionadas às novas definições de sujeito e de objeto. A partir dessas questões podemos questionar: A ética ou uma educação em valores morais estaria no 
campo disciplinar ou teríamos, nessa perspectiva, a possibilidade de ir além das mesmas? Quais seriam as ações e métodos necessários para abordar essa questão? Buscamos uma maior discussão desses aspectos na próxima seção.

\section{ÉTICA E EDUCAÇÃO EM VALORES MORAIS NUMA PERSPECTIVA TRANSDISCIPLINAR}

Antes de entrarmos na discussão pretendemos esclarecer que, quando nos referimos a ética, não estamos fazendo distinção ao termo moral; não pelo fato de fixar posição entre diferenciar ou considerar como sinônimos os termos, mas pela limitação de nossos estudos e por considerar que, nesse trabalho, poderia tirar o foco da discussão. De momento nos valemos de Canto-Sperber (2005), que entende que não há nenhuma dúvida sobre o fato de que os termos moral e ética designam o mesmo domínio de reflexão. Da mesma forma, Morin (2011) considera os termos inseparáveis e que, muitas vezes, se recobrem. Dessa maneira, utilizaremos indiferentemente ambos quando nos referimos à educação em valores morais.

Sobre o estabelecimento de um conceito sobre valor ou valores morais, sabemos que isso é tarefa difícil para se chegar a um consenso. Provisoriamente, buscamos em Santin e Silva (2005) uma definição de valor e valores morais como ponto de partida para a discussão. O mesmo foi publicado no Dicionário Crítico da Educação Física em forma de verbete, quando consideram que os valores morais

[...] são aqueles que enunciam normas, que determinam o dever-ser de nossos sentimentos, nossos atos, nossos comportamentos. Estabelecem obrigações e avaliam intenções e ações segundo o critério do correto e do incorreto. [...]. Os valores morais determinam o que é o bem, o mal e a felicidade, ou seja, são aqueles que estabelecem quais atos, sentimentos, intenções ou comportamentos devemos ter ou fazer para alcançarmos o bem e a felicidade e aqueles considerados condenáveis ou incorretos do ponto de vista moral $(2005$, p. 419).

O cultivo maior ou menor de valores geralmente está relacionado à família, à classe social ou qualquer outra instituição ou grupo do qual fazemos parte. Reconhecendo a importância dessa discussão, precisamos entender como a mesma se instaura no processo educativo, em que vemos algumas dificuldades em traduzi-las para o nível prático e objetivo em termos de projeto pedagógico. Além dessa dificuldade, o que também presenciamos, em muitos casos, é a escola se abster desse debate transferindo a responsabilidade para a família ou para outras instâncias da sociedade.

Permeando o debate, uma série de questões são instauradas: Como podemos olhar uma educação em valores éticos e morais a partir das disciplinas, áreas ou funções do currículo? É possível encontrar certa unidade em termos de valores no processo educativo? $\mathrm{O}$ que se pode fazer de concreto para que um projeto transdisciplinar possa dar conta do debate para uma educação em valores necessária para o desenvolvimento integral? $\mathrm{O}$ que podemos fazer para incrementar o conhecimento pedagógico que dê respostas às necessidades humanas atuais? Não possuímos as respostas para as mesmas, mas alguns subsídios para uma reflexão. Consideramos a escola um lócus privile- 
giado para o debate dessa relação e, consequentemente, para o conhecimento do mesmo. Morin (2011) se apoia em Pascal para afirmar a conduta moral de ter conhecimento das condições objetivas, estabelecendo a relação entre o saber e o dever.

A partir de algumas leituras na busca pelo nosso referencial teórico ou ponto de partida para delinear nosso estudo, encontramos, na obra Transdisciplinaridade, criatividade e educação: fundamentos ontológicos e epistemológicos, de Maria Cândida Moraes e Juan Miguel Batalloso Navas (2015a), bons subsídios que poderão nortear as discussões e que pretendemos apresentar. A referida obra associa a transdisciplinaridade a uma visão complexa da realidade, como atitude epistemológica e metodologia aberta capaz de assegurar o espaço de interconexão disciplinar. Na referida obra, encontramos na transdisciplinaridade elementos, pistas ou possibilidades de contribuição para uma definição de princípios e diretrizes para a sua execução no processo educativo.

Como asseveramos anteriormente, essa discussão nos provoca e gostaríamos de encontrar algumas respostas para as questões formuladas anteriormente, que, por sinal, são muitas, podendo servir como base para o nosso debate. O tema, que outrora foi iniciado por diversos autores, ainda é pouco explorado no campo educacional e ainda carece de muitas respostas que contemplem todas as indagações, principalmente no que se refere à possibilidade concreta de efetivação na escola ou de experiências realizadas com êxito. O foco da obra não aborda uma educação em valores morais. mas uma estruturação ou elementos para a criação de uma metodologia transdisciplinar, uma vez que a educação é concebida como processo permanente de ação transformadora. A obra contribui para os interessados em uma educação transdisciplinar, educação essa que pode possibilitar uma mudança na convivência humana.

Maria Cândida de Moraes credencia-se a fazer a interlocução desse debate, pois coordena o grupo de pesquisa Ecologia dos Saberes e Transdisciplinaridade (Ecotransd/ $\mathrm{UCB} / \mathrm{CNPq}$ ), com diversas obras publicadas sobre o tema. O colaborador na obra, Juan Miguel Batalloso Navas, também é pesquisador no grupo mencionado e desenvolve cursos de formação na temática sobre educação em valores. Os mesmos consideram que esse aspecto se constitui em desafio importante, levando para a necessidade de as discussões éticas se fazerem presentes nas ações e relações do contexto educativo e nos respectivos processos pedagógicos. Para os autores, a ética "apresenta-se na educação transdisciplinar como exigência moral, como um dever a ser cumprido, como algo importante a ser observado em todas as instâncias e circunstâncias educacionais" ( $p$. 103-104). Os autores, utilizando-se de Morin (2005), entendem que o ato ético e moral se configura numa religação com o outro, com a comunidade, com a sociedade e com a espécie humana.

Ainda conforme os autores citados anteriormente, a educação transdisciplinar privilegia a questão ética, desde que seja uma ética que não se propõe à fragmentação, redução, desunião e mutilação das relações, como muitas vezes visto no pensamento da escola clássica ou tradicional. Nessa discussão não se pensa a ética como disciplina isolada, mas que esta está presente em todas elas, além de estar também em todas as ações, falas e gestos daqueles que compõem o processo educativo. Os mesmos requerem da escola e da comunidade educacional ações voltadas para a solidariedade, responsabilidade e sustentabilidade, sempre levando em consideração a diversidade. 
Moraes e Navas (2015a) fornecem possíveis indicadores que caracterizam uma escola transdisciplinar, apresentando uma matriz representativa de ações que uma escola transdisciplinar deve realizar. Essa matriz constitui-se numa espécie de mandala com 12 vértices compostos por 4 triângulos em movimento, com todas as dimensões entrelaçadas. Neles situam duas grandes circunferências: a ética e o eros. Entendem que essa matriz deva ser iluminada por ações e posturas éticas voltadas para uma escuta sensível. A partir dessa matriz definem finalidades educativas inseridas em 4 dimensões: dimensão ecossocial e planetária; dimensão psicofísica, corporal, emocional e cognitiva; dimensão criativa e estética e dimensão política.

A preocupação desse projeto é o desenvolvimento humano, no qual o ponto de partida são projetos integradores de diferentes disciplinas procurando trabalhar de forma integrada o sentir-pensar-agir, articulando as relações indivíduo/sociedade/natureza. Os autores citam que "as lógicas que prevalecem são inclusivas, não dualistas, que estão presentes a cooperação, a solidariedade, a diversidade" (p. 109, grifo nosso). Morin (2011) aponta a necessidade de intervenção em valores como liberdade, equidade, solidariedade, verdade e bondade.

Hoje, da forma como estão organizados os conteúdos disciplinares, é possível perceber que existe um olhar para o pensamento crítico e a vivência da autonomia? Está em aberto o desenvolvimento de valores como respeito, alteridade, sustentabilidade, integridade, amorosidade, entre outros? Entendemos que na escola a inteligência cognitiva a ser desenvolvida nas disciplinas, conteúdos e projetos é importante, porém o que questionamos é a supervalorização desse enfoque em detrimento do que acontece com o ser humano em seu desenvolvimento. Entendemos e concordamos com Paul (2015, p. 9), que assevera que "[...] O ensino não pode ser apenas uma transmissão de saberes e de técnicas; ele deve também favorecer o desenvolvimento de valores éticos". Nesta mesma direção, Moraes e Navas (2015a, p. 83) ressalta que

[...] a abordagem transdisciplinar ajuda-nos a promover a alteridade, a resgatar 0 respeito ao pensamento do outro que, embora seja diferente do meu, é absolutamente legítimo [...] reconhecendo a importância dos conhecimentos antigos e a necessidade de explorar outras maneiras de ser/conhecer, de viver/conviver e aprender.

Precisamos de uma escuta sensível que possa contribuir nas necessidades nas quais estamos implicados e envolvidos. Uma educação que se pretende ser integral necessita levar em consideração o sujeito, dotado de diferentes capacidades e habilidades que precisam ser consideradas num todo harmônico. Ou seja,

[...] não podemos conceber o ser humano sem lembrar que ele é simultaneamente um ser físico, biológico, social, cultural, psíquico e espiritual e que todas essas dimensões estão presentes nos atos de aprender e conhecer. Todos esses aspectos têm implicações significativas nos processos de mediação pedagógica, bem como em todos os processos educacionais, já que não aceitamos a escola reprodutora do conhecimento processado linearmente nem discurso pedagógico de teor autoritário [...] (MORAES; NAVAS, 2015a, p. 51). 
Uma escola transdisciplinar tem de considerar o desenvolvimento intelectual e moral que não é nutrido exclusivamente pelos conteúdos das disciplinas, mas, ao mesmo tempo, pelas relações sociais, afetivas e emocionais, refletidas pelo contexto e condição cultual e histórico-social. Numa prática curricular transdisciplinar devemos aprender a considerar a pluralidade das referências, levando em consideração os conteúdos não disciplinares emergentes nas salas de aula, tendo como foco principal o desenvolvimento humano (MORAES; NAVAS, 2015a).

No plano da discussão ética, Morin (2011) chama a atenção para o fato de cada vez mais termos um aumento nas demandas éticas. Da mesma forma, entendemos a necessidade de discutirmos alguns valores morais que, aos nossos olhos, parecem ter se perdido. Essas demandas acontecem nos mais diversos segmentos da sociedade, portanto não é somente na escola que necessitamos problematizar esse tema. Também é importante salientar que não reside apenas na escola a solução para esse embate. Assim como o autor, em determinado momento, questiona se há necessidade de uma nova ética, nos deparamos, frequentemente, questionando se há necessidade de novos valores.

O próprio autor aponta uma saída para essa discussão. Para ele, não se trata de estabelecer novos princípios morais ou éticos adaptados ao nosso tempo, mas, sim, regenerar a própria ética. Somos uma sociedade onde impera o egoísmo, na qual a regeneração moral precisa incorporar os preceitos da autoética para reativar nossas potencialidades altruístas e comunitárias. Essa regeneração ética, segundo Morin (2011), somente pode acontecer numa complexa transformação humana, social e histórica. Pensar numa educação de valores morais numa perspectiva transdisciplinar, nos obriga a esclarecermos e delimitarmos a quais valores nos referimos.

A discussão sobre quais valores não é recente. Algumas questões foram lançadas por Comte-Sponville (1996, p. 133): "Qual fundamento, para quais valores"? Diversos autores propalam uma crise de valores: Significa que os valores perderam seu valor? E quais estão em crise? $O$ autor considera que a moral deve ter uma origem e que agir moralmente é a possibilidade de poder se colocar no lugar dos outros. Entende que os valores morais são aqueles que vão ao sentido da vida, da sociedade e dos seus interesses, na direção da razão e do universal e no sentido do amor, cada qual com seus limites.

Além da discussão acerca de quais valores, o que encontramos também é se isso é tarefa da escola ou não. Ou, retomando o velho dilema grego: A virtude pode ser ensinada? Caso seja a resposta afirmativa, de que forma deve ocorrer? Um autor que dedica suas reflexões a essa temática é Yves de La Taille, com várias obras publicadas, que concorda que a escola não pode se calar a respeito dessa temática, portanto, a mesma pode e deve ser ensinada na escola. La Taille mostra que há propostas pedagógicas de educação do juízo moral e que existem muitas pessoas engajadas nessa discussão. Algumas alternativas são consideradas pelo autor na obra Formação Ética: do tédio ao respeito de si, publicada em 2009. Para ele, a possibilidade ocorre: por meio de o ensino religioso discutir a moralidade, pelas aulas de filosofia e ciências humanas, em forma de 
disciplina de educação moral ou recuperando a experiência proposta pelos $\mathrm{PCNs},{ }^{4}$ ou seja, de modo transversal. $\mathrm{O}$ autor aponta os limites e possibilidade de cada metodologia. Interessa-nos, nesse momento, reforçar a tese de que a escola pode promover essa discussão.

Para Alencar e Müller (2017, p. 14), "A educação moral é um tema que filósofos e teóricos da educação, psicologia, sociologia, antropologia e das demais áreas do conhecimento humano têm estudado durante séculos. ${ }^{5 "}$ Nota-se, portanto, que a discussão não é recente, porém ainda é válida em nosso tempo. Além de não perder validade, as autoras afirmam que as discussões ultrapassam as fronteiras do contexto brasileiro, sendo realizadas em diversos países. ${ }^{6}$ Mesmo que em muitos casos a perspectiva dos autores seja diferente, o que as mesmas têm em comum é a que a educação moral busca a formação de sujeitos autônomos.

Consideramos que trabalhar uma educação em valores morais, numa perspectiva transdisciplinar, deve acontecer a partir de um projeto institucional, ${ }^{7}$ que serve de base para todas as ações da escola, configurando-se numa boa estratégia educacional para abordar os respectivos valores de acordo com as emergências do contexto em questão. Caso o projeto institucional não seja possível para instituir, de forma imediata, uma saída para trabalhar a educação em valores morais, seria utilizada a metodologia baseada em projetos de aprendizagem e desenvolvimento comunitário. Trabalhar por projetos permite desenvolver diversas capacidades que não são reduzíveis apenas aos aspectos cognitivos. Como já citado anteriormente, precisamos, sim, da inteligência para o enfrentamento e resolução de diversos problemas ou conflitos, porém devemos considerar que essa inteligência está associada à ética e aos princípios morais sempre em um contexto de valores. Para Patrick Paul (2015, p. 9), “[...] é importante promover os valores, muitas vezes esquecidos, que desenvolvam nossas virtudes e fundam nossa humanização $[. . .]^{\prime \prime}$.

Os projetos possibilitariam o desenvolvimento de atitudes que favoreçam a reflexão ética a partir da análise de nossa conduta, convivência e tomadas de decisão (BATALLOSO, 2015). O autor continua afirmando que

\footnotetext{
${ }^{4}$ Os Parâmetros Curriculares Nacionais (PCNs), publicados em 1997, apresentavam como um dos temas transversais o ensino da Ética. Para tal, propunha como conteúdo o diálogo, justiça, solidariedade e respeito mútuo. O documento faz alusão a não exitosa experiência do ensino obrigatório da moral e do civismo por meio da disciplina Educação Moral e Cívica, deixando claro que o documento se afasta dessa concepção. O tema da ética no PCN foi abordado do ponto de vista da Psicologia, com base no construtivismo.

${ }^{5} \mathrm{O}$ que nos parece um indicativo dessa possibilidade é a preocupação das várias ciências em torno do tema, fato que consideramos poder ser refletido pelo viés da transdisciplinaridade.

${ }^{6}$ Estados Unidos (GILLIGAN, 1982; TURIEL, 1983; NUCCI, 2000); Portugal (ESTEVÃO, 2006); Espanha (PUIG, 1998, 2000, 2007; DELVAL, 2006); México (BERTUSSI, 1998); França (DELORS, 1996 [2010]; BARRERE; MARTUCCELLI, 2001; MORIN, 2007); Chile (MATURANA, 1998); Brasil (CAMINO, 1998, LA TAILLE, 1996, 1998, 2006a, 2006b, 2009) entre outros.

Defendemos uma educação moral no âmbito institucional, onde "[...] a instituição escolar, como um todo, deve ser um espaço democrático, onde os valores morais estejam presentes: nas aulas, nos trabalhos cooperativos, nos projetos, na organização de festas e eventos culturais esportivas, entre outros". (ALENCAR; MÜLLER, 2017, p. 19). Conforme Morin (2005, p. 176) "[...] se tentamos pensar no fato de que somos seres ao mesmo tempo físicos, biológicos, sociais, culturais, psíquicos e espirituais, é evidente que a complexidade é aquilo que tenta conceber a articulação, a identidade, e a diferença de todos esses aspectos [...]". Para nós, pensar num desenvolvimento integral é assumir a responsabilidade por todas essas dimensões sem sobrepor nenhuma em detrimento da outra.
} 
[...] talvez, o projeto mais inteligente dos seres humanos seja o projeto ético, o projeto de dotar-nos de valores que nos façam plenamente humanos e nos permitam viver/conviver com sentido e com os demais, porque, ao fim, a característica fundamental da inteligência é sua capacidade de criar fins, de inventar e alcançar objetivos, de idealizar e assumir valores. Daí que devemos defender plenamente que a escola criativa e transdisciplinar do futuro seja necessariamente ética em todos os seus elementos funcionais, materiais e pessoais, porque a ética é, sem dúvida, a forma mais suprema de inteligência e o modo mais inteligente de resolver problemas e satisfazer necessidades (. 135).

Podemos encontrar nas propostas pedagógicas das instituições os pilares necessários e essenciais para os processos educativos: aprender a ser, aprender a conviver, aprender a aprender e aprender a comprometer-se. O que se presencia nessa definição, porém, é uma dupla moral: um apelo ao discurso sobre determinados valores, mas que, na prática, ocorre o distanciamento desses valores. Esse é um dilema a ser superado, pois, aparentemente, temos um indicativo de como devemos pensar a estrutura organizacional da escola, mas, na realidade, não buscamos instituir ou materializar essas questões. Por que isso acontece?

\section{CONSIDERAÇÕES FINAIS}

Chegamos ao final do texto, porém as análises são experimentais, portanto suscitam maior aprofundamento. Por hora percebemos que a fragmentação do conhecimento ainda está evidente e se reproduz na organização chamada escola. Precisamos de um movimento que nos conduza numa perspectiva de superação do processo de separação dos conteúdos e conhecimentos disciplinares. Precisamos encontrar caminhos na educação que, como sugere Morin (2000), seria a Educação do Futuro, que esteja centrada na condição humana, e abandonar a ideia do homem e do mundo divididos em partes e que a soma das mesmas dê conta da totalidade. Como, no entanto, pensar no desenvolvimento integral ${ }^{8}$ num modelo fragmentado de escola?

É necessário perceber o ser humano inserido em uma complexidade de saberes, quando nenhum saber é mais importante que o outro. Pensar uma educação transdisciplinar, fundamentada na complexidade das relações entre os conhecimentos, pode tornar-se uma alternativa, além de estabelecer meios de se compreender diversos assuntos por diferentes perspectivas. Nesse sentido, entendemos que uma educação em valores morais não pode ficar alheia a essa "formação", pois as relações estabelecidas entre os humanos são complexas e impregnadas de questões éticas e morais, ou, mesmo, com a falta delas. Ética e valores morais são temas que transitam por todos os componentes curriculares. Pensar em discussões sobre justiça, diálogo, solidariedade e respeito mútuo contribui para a elaboração de uma consciência aberta à construção de uma nova possibilidade de escola.

\footnotetext{
${ }^{8}$ Conforme Morin $(2005$, p. 176) “[...] se tentamos pensar no fato de que somos seres ao mesmo tempo físicos, biológicos, sociais, culturais, psíquicos e espirituais, é evidente que a complexidade é aquilo que tenta conceber a articulação, a identidade, e a diferença de todos esses aspectos [...]". Para nós, pensar num desenvolvimento integral é assumir a responsabilidade por todas essas dimensões sem sobrepor nenhuma em detrimento da outra.
} 
Não estamos defendendo o que La Taille (2009) chama de escola de virtudes, onde determinados valores são instituídos de forma instrumental e utilitarista e em detrimento do conhecimento cognitivo ou sistematizado. Conforme o autor, temos a crença que a educação tem legitimidade para apresentar aos alunos determinados princípios e valores morais. Na educação existe o contato entre os seres humanos e isto pode contribuir para o convívio social como uma forma de o ser humano se constituir verdadeiramente como tal. É pela educação que estes contatos podem acontecer com uma riqueza que dificilmente outra instituição poderá oferecer. Essa riqueza poderá ser aproveitada entendendo-se a complexidade das relações que se estabelecem.

Infelizmente nosso sistema educacional ainda está baseado na separação dos saberes em disciplinas, e necessita de uma reforma anterior ao sistema, uma reforma de pensamento. Precisamos conectar os conhecimentos para reconhecer os problemas globais sob a ótica da ou das complexidades que cercam as relações entre os indivíduos e a sociedade. Reformar o pensamento e a educação é compreender as necessidades políticas, sociais e éticas das quais somos parte. Precisamos promover valores que possam atender aos desafios contemporâneos, como autonomia, respeito, cooperação, pensamento crítico, solidariedade, capacidade para resolução de problemas complexos, altruísmo e aptidão para o diálogo, entre outros.

Concorda-se que na escola não é possível somente nos preocuparmos com o ensino ou transmissão de conhecimentos por intermédio dos conteúdos escolares. O que se questiona é a possível ausência de discussões em torno dos valores morais. Quando se afirma que no espaço escolar se trabalha uma educação de valores pelo fato de os alunos "obedecerem" a regras e normas, como o uso do uniforme, a fila para entrar na sala, a utilização ou não dos celulares e diversas outras normas, principalmente de conduta, é reduzir o papel da educação para a possibilidade de contribuir numa formação voltada para a autonomia dos discentes.

Para essa formação não estamos afirmando que a transdisciplinaridade é a chave para a solução de todos os problemas relativos a essa discussão, porém entendemos que possa se configurar num movimento que busca romper com os condicionantes que reinam em nossa sociedade, que parecem querer insistir com a fragmentação do saber, do dever, das relações. Aliado a essa fragmentação, percebe-se um movimento tímido em relação à educação em valores morais. Não estamos querendo recuperar os temas transversais apresentados no final dos anos 90 do século 20, e sim chamar a atenção para o silêncio das escolas a respeito da educação moral.

Será a transdisciplinaridade uma realidade educacional viável que não fique no plano da discussão teórica? Entendemos que possam existir estratégias pedagógicas para uma educação em valores morais, e a mesma, como citado anteriormente, aparece como saída, pois, na interação entre as disciplinas, se poderá obter como produto um conhecimento transdisciplinar que vai além de todas elas; um conhecimento que transcende todas as fronteiras entre as disciplinas. A educação em valores morais poderá ser esse produto? Acreditamos que a escola não pode silenciar para essa questão. Pensamos que as instituições devem ter um consenso sobre alguns valores morais fundamentais a serem desenvolvidos na e pela escola. Como fazer? A quem recorrer? Esse é o nosso desafio para o qual todos estamos convocados. 


\section{REFERÊNCIAS}

ALENCAR, Heloisa Moulin de; MÜLLER, Adriana. Educação moral: procedimentos possíveis no contexto escolar. In: DANI, Lúcia Salete Celich; FREITAS, Lia Beatriz de Lucca (org.). Reflexões sobre educação moral. Campinas, SP: Mercado das Letras, 2017.

ARAÚJO, Ulisses Ferreira de. A construção social e psicológica dos valores. In: ARAÚJO, U. F. de; PUIG, J. M.; ARANTES, V. A. (orgs.). Educação e valores: pontos e contrapontos. São Paulo: Summus, 2007.

BATALLOSO, Juan Miguel. A escola criativa e transdisciplinar do futuro. In: MORAES, Maria Cândida; NAVAS, Juan Miguel Batalloso (col.). Transdisciplinaridade, criatividade e educação: fundamentos ontológicos e epistemológicos. 11. ed. Campinas: Papirus, 2015.

CANTO-SPERBER, Monique. A inquietude moral e a vida humana. São Paulo: Loyola, 2005.

COMTE-SPONVILLE, André. Uma moral sem fundamento. In: MORIN, Edgar; PRIGOGINE, llya et al. A sociedade em busca de valores: para fugir à alternativa entre o cepticismo e o dogmatismo. Tradução Luís M. Couceiro Feio. Lisboa: Instituto Piaget, 1996.

LA TAILLE, Yves de. Formação ética: do tédio ao respeito de si. Porto Alegre: Artmed, 2009.

LORENZO, Cláudio. O Método 6: ética. Ciência \& Saúde Coletiva, 13(2), p. 543-547, 2008.

MORAES, Maria Cândida; NAVAS, Juan Miguel Batalloso (col.). Transdisciplinaridade, criatividade e educação: fundamentos ontológicos e epistemológicos. 11. ed. Campinas: Papirus, 2015a.

MORAES, Maria Cândida;, NAVAS, Juan Miguel Batalloso. Um olhar complexo e transdisciplinar sobre ética e educação. In: BEHRENS, Marilda Aparecida; ENS, Romilda Teodora (org.). Complexidade e transdisciplinaridade: novas perspectivas teóricas e práticas para a formação de professores. Curitiba: Appris, 2015b.

MORIN, Edgar. Introdução ao pensamento complexo. 5. ed. Porto Alegre: Sulina, 2015.

MORIN, Edgar. O método 6: ética. Tradução Juremir Machado da Silva. 4. ed. Porto Alegre: Sulina, 2011.

MORIN, Edgar. Ciência com consciência. Tradução Maria D. Alexandre e Maria Alice Sampaio Dória. 8. ed. Rio de Janeiro: Bertrand Brasil, 2005.

MORIN, Edgar. A cabeça bem-feita: repensar a reforma, reformar o pensamento Tradução Eloá Jacobina. 8. ed. Rio de Janeiro: Bertrand Brasil, 2003.

MORIN, Edgar. Os sete saberes necessários à educação do futuro. Tradução Catarina Eleonora F. da Silva e Jeanne Sawaya. 2. ed. São Paulo: Cortez. Brasília, DF: Unesco, 2000.

NICOLESCU, Basarab. Um novo tipo de conhecimento: transdisciplinaridade. In: Educação e Transdisciplinaridade, Cetrans, 1999. Disponível em: http://unesdoc.unesco.org/images/0012/001275/127511por. pdf.

PAUL, Patrick. Prefácio. In: MORAES, Maria Cândida; NAVAS, Juan Miguel Batalloso (col.). Transdisciplinaridade, criatividade e educação: fundamentos ontológicos e epistemológicos. Campinas: Papirus, 2015.

SANTIN, S.; SILVA, M. R. S. da. Valor. In: GONZÁLEZ, F. J.; FENSTERSEIFER, P. E. Dicionário crítico de Educação Física. ljuí: Ed. Unijuí, 2005. p. 419. 